\title{
HIV and the tuberculosis "set point": how HIV impairs alveolar macrophage responses to tuberculosis and sets the stage for progressive disease
}

\author{
Sara C. Auld ${ }^{1,2^{*}}$ (D) and Bashar S. Staitieh ${ }^{1}$
}

\begin{abstract}
As HIV has fueled a global resurgence of tuberculosis over the last several decades, there is a growing awareness that HIV-mediated impairments in both innate and adaptive immunity contribute to the heightened risk of tuberculosis in people with HIV. Since early immune responses to Mycobacterium tuberculosis (Mtb) set the stage for subsequent control or progression to active tuberculosis disease, early host-pathogen interactions following Mtb infection can be thought of as establishing a mycobacterial "set point," which we define as the mycobacterial burden at the point of adaptive immune activation. This early immune response is impaired in the context of HIV coinfection, allowing for a higher mycobacterial set point and greater likelihood of progression to active disease with greater bacterial burden. Alveolar macrophages, as the first cells to encounter Mtb in the lungs, play a critical role in containing Mtb growth and establishing the mycobacterial set point. However, a number of key macrophage functions, ranging from pathogen recognition and uptake to phagocytosis and microbial killing, are blunted in HIV coinfection. To date, research evaluating the effects of HIV on the alveolar macrophage response to Mtb has been relatively limited, particularly with regard to the critical early events that help to dictate the mycobacterial set point. A greater understanding of alveolar macrophage functions impacted by HIV coinfection will improve our understanding of protective immunity to Mtb and may reveal novel pathways amenable to intervention to improve both early immune control of Mtb and clinical outcomes for the millions of people worldwide infected with HIV.
\end{abstract}

Keywords: Tuberculosis, HIV, Macrophages, Coinfection, Innate immunity

\section{Introduction}

Although tuberculosis incidence declined worldwide over the course of the $20^{\text {th }}$ century [1-4], these gains were quickly reversed with the onset of the HIV epidemic in the 1980s [5]. Tuberculosis is now the leading global killer among infectious diseases and the leading cause of death among people with HIV [6]. The profound T cell depletion induced by HIV has long been recognized as a

\footnotetext{
*Correspondence: sauld@emory.edu

1 Emory University School of Medicine, Atlanta, GA, USA

Full list of author information is available at the end of the article
}

significant driver of the tuberculosis epidemic in people with HIV [7, 8]. However, there is growing awareness that HIV-mediated impairments in innate immunity also contribute to the increased risk of tuberculosis in this vulnerable population. These HIV-mediated impairments in innate immunity are particularly relevant early in $\mathrm{Myco-}$ bacterium tuberculosis (Mtb) infection, prior to the onset of adaptive immune responses [9] and, by impairing early control of $M t b$, set the stage for accelerated progression to active tuberculosis disease.

The pattern of early immune control setting the stage for longer term control-and clinically meaningful endpoints-parallels our understanding of the HIV set point. 
It was first recognized in the late 1990s that the HIV viral load soon after seroconversion, i.e., the HIV set point, is predictive of disease progression [10, 11]. Following infection, HIV replicates unchecked until an initial, albeit ineffective, host immune response develops and the set point is established [12-14]. When viewed through this same lens, early host-pathogen interactions following $M t b$ infection can be thought of as establishing a "mycobacterial set point" (Fig. 1). Unlike the set point in HIV, which occurs after an ineffective adaptive immune response, the mycobacterial set point is established before the onset of adaptive immunity.

Although we currently lack the tools to measure the mycobaterial set point clinically, this theoretical construct provides a framework for understanding early immune responses to $M t b$, particularly those of the alveolar macrophage. While a multitude of cell types, including recruited interstitial macrophages, dendritic cells, and neutrophils, are infected prior to the onset of adaptive immunity [15], work by Cohen and others has confirmed the importance of the alveolar macrophage to the early $M t b$ response [16]. As we will emphasize in this review, a focus on this critical early period and the mycobacterial set point are useful in understanding the relative impacts, both on a cellular and clinical level, of various host and pathogen impairments that occur in the context of coinfection with $M t b$ and HIV. The concept of a mycobacterial set point also provides us with an overall index of immune health in the context of HIV/Mtb coinfection and thereby offers a useful gauge of efficacy when specific pathways are manipulated for therapeutic benefit. Host immunity to $M t b$ remains poorly understood, but a focus on the role of alveolar macrophages in establishing a mycobacterial set point and on alterations in macrophage control in the context of HIV coinfection has the potential to yield great insight into some of the earliest immune events in $M t b$ infection.

Although $M t b$ - and HIV-mediated impairments in pulmonary innate immunity and alveolar macrophage function have been reviewed elsewhere $[17,18]$, the impact of these impairments in the context of coinfection has not been well described. In this review, we will explore how HIV coinfection makes alveolar macrophages, the first cells to encounter $M t b$, more permissive of early mycobacterial growth and is therefore likely to increase the mycobacterial burden at the point at which adapative immunity is activated and the mycobacterial set point is established [16]. By curtailing early immune control and delaying the onset of adaptive immunity, HIV coinfection leads to a higher mycobacterial set point and, consequently, a greater bacterial burden (Fig. 1).

In order to demonstrate the utility of the mycobacterial set point framework, we will first review epidemiologic data supporting the importance of innate immunity in people with tuberculosis and HIV coinfection. We will then discuss some of the model systems that are used to study macrophage responses to $M t b$ and HIV and animal model findings in support of a mycobacterial set point. We will then highlight existing data on alveolar macrophage functions-from macrophage phenotype, key cytokines, and oxidative stress, to pathogen recognition and phagocytosis, cell death pathways, and activation

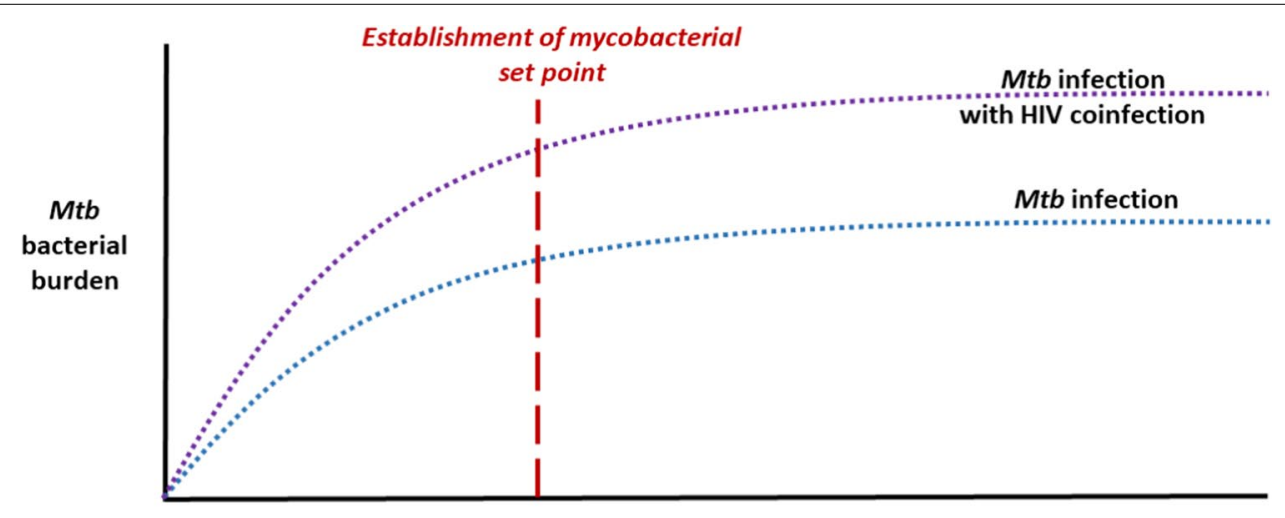

Time from Mtb infection

Fig. 1 Graphical depiction of the mycobacterial set point as a theoretical construct, represented as the Mycobacterium tuberculosis (Mtb) bacterial burden after infection, either alone or in the context of HIV coinfection. After infection, Mtb bacterial burden increases until adaptive immunity is activated, thereby establishing the mycobacterial set point. Alveolar macrophages, the first cells to encounter Mtb, are an important component of the early innate immune response to $M t b$. As reviewed in the main text, the mycobacterial burden at the point of adaptive immune activation plays a important role in the subsequent control of infection and progression to active tuberculosis disease. In the case of HIV coinfection, impairments in alveolar macrophage functions lead to poor early immune control of Mtb which, in turn, leads to a higher mycobacterial set point and greater Mtb bacterial burden at the time when adaptive immunity is activated 
of adaptive immunity-that are impacted by either $M t b$ infection, HIV infection, or coinfection. The examples we provide, which come from a range of cell types and organ systems, including primary alveolar macrophages, monocyte-derived macrophages, and cell lines, are not meant to be exhaustive or comprehensive. Rather, our goal is to provoke further inquiry and investigation into this critical area by offering a framework by which to contextualize studies in the field. We will close the review by highlighting several promising avenues for studying the mycobacterial set point in humans, in order to underscore the potential benefit of this concept as a framework for clinically relevant research.

\section{Epidemiologic data for the role of innate immunity in HIV and tuberculosis}

From the earliest days of the HIV epidemic it has been clear that tuberculosis outcomes were markedly worse in people with HIV. In a series of nosocomial tuberculosis outbreaks among people with HIV in the early 1990s, the overwhelming majority of patients died, often within a month or two of their diagnosis [19-21]. These individuals had very advanced HIV, which undoubtedly contributed to their high mortality rates [21]. However, their rapid progression from exposure to active disease, in a time frame prior to the expected onset of adaptive immunity, suggests that impaired innate immunity was likely a contributing factor. Similarly, in a study of South African gold miners newly infected with HIV, the risk of tuberculosis disease was found to increase very early in the course of HIV infection, when CD4 counts would still be in a normal range [22]. Another study from South Africa found that people with HIV on antiretroviral therapy (ART) with normal CD4 counts had four times the risk of tuberculosis than people without HIV [23]. Likewise, in Italy, a setting with a low burden of both HIV and tuberculosis, nearly a third of patients diagnosed with HIV-associated tuberculosis in one study had been receiving ART for a median of 27 months, at which point CD4 counts would typically have reached a normal range [24]. Taken together, these data offer epidemiologic evidence that defects in both innate and adaptive immunity are likely to contribute to the greater risk of tuberculosis in people with HIV. While these clinical observations cannot establish mechanism or causality, they do provide a rationale for pursuing further basic science and translational studies to better understand the role of innate immunity in controlling $M t b$ infection.

\section{Model systems for studying alveolar macrophage responses to Mtb and HIV}

Over the last century, scientists from successive eras have made remarkable discoveries by bringing the newest available techniques to bear on their investigations of $M t b$, with various model systems employed over time. While each system has distinct advantages and disadvantages in addressing particular questions, the sheer volume of data derived from the many available systems can make it hard to develop a coherent narrative regarding $M t b$ infection in humans. Although a full review of these features of the tuberculosis literature is beyond the scope of this review, we will offer a brief overview of the main characteristics of some of the major models to provide context for the reader $[25,26]$.

Despite their inability to model sophisticated cellular interactions, in vitro systems have long been used as tools for studying $M t b$ [27]. A variety of myeloid cell lines have been employed, and are often helpful in quantifying cytokine and other signaling responses to $M t b$. In addition, due to the ease with which in vitro systems can be manipulated, studies with primary macrophages from animal models have enabled investigators to dissect the roles of individual proteins and pathways in the $M t b$ response $[28,29]$. Finally, human primary cells have been used in a variety of ways, including induced pluripotent stem cells, human macrophages, granuloma models, and many more. Each system has proven useful in addressing different aspects of the $M t b$ response, but all are hampered by their inability to coordinate the full spectrum of in vivo responses. An additional challenge is the conflation of different types of macrophages, whether from cell-lines, animal models, or humans, as a homogenous population. Rather, there is a growing appreciation of the distinctions between tissue-derived and bone-marrow derived macrophages, from their ontogeny to functional capacity and self-maintenance [30-32]. These distinctions are highly relevant to this review, as bone-marrow derived macrophages do not become polarized in the same manner as alveolar macrophages following $M t b$ exposure, and thus cannot be expected to behave the same [33]. However, given challenges in obtaining primary alveolar macrophages, particularly from humans [34], many studies are conducted with derived cells.

With regards to animal systems, ease of use in handling the zebrafish-Mycobacterium marinum model has made it a powerful tool for the study of $M t b$ [35]. Several key components of the human response to $M t b$ are present in zebrafish, including the leukotriene A4 hydrolase locus, and it has been used to study everything from treatment strategies for drug-resistant $M t b$ to vaccine development. The mouse model has the virtue of capturing vertebrate, mammalian immune responses in a reproducible, easily scalable system. However, different mouse strains have different levels of susceptibility to $M t b$ and mice do not typically form granulomas or cavities [36]. As a result, the mouse model tends to be suited for studies 
of cell-mediated immunity and drug development, but less useful for studies of human clinical outcomes [37]. Guinea pigs provide another small animal model, with the benefit of recapitulating lung necrosis and other human features, but challenges in measuring their immune responses has historically limited their widespread use [25]. Rabbits have also provided an effective model system for $M t b$ research, largely due to the fact that the structural similarities between their lungs and human lungs leads to similar pathology in response to $M t b$. That said, their larger size and the greater resources required to utilize them has limited their broad applicability $[36,38]$. Finally, non-human primates, particularly rhesus and cynomolgus macaques, have marked genetic and immunologic similarities to humans and, as such, have yielded significant advances in our understanding of host-pathogen interactions and the potential for vaccineinduced protection in recent years [39, 40]. However, given the vast resources needed to sustain these animals, there are a limited number of research centers capable of conducting non-human primate studies.

\section{Evidence to date for a "mycobacterial set point"}

While in-depth analysis of early immunologic events in human $M t b$ infection remains challenging for the reasons discussed above, Poulsen and others established over 50 years ago that tuberculin skin test (TST) conversion in humans, an indicator of the onset of the adaptive immune response, generally occurred by 6 weeks after exposure [41-43]. Poulsen also determined that this period prior to TST conversion is not a time of immunologic quiescence; rather, many individuals had evidence of a robust inflammatory response with fever and elevated inflammatory markers.

Since those landmark studies, much of our understanding of these early events has relied on data from animal models. Experiments in rabbits and guinea pigs by Lurie, Smith, and Harding, established that macrophages provide a niche within which $M t b$ multiplies logarithmically during early infection $[44,45]$. Others have demonstrated that the onset of adaptive immunity in response to $M t b$ is indeed delayed, arising in part from delayed activation of CD4+ T cells within local lymph nodes [46, 47]. This delay of several weeks, as compared to several days with organisms such as Salmonella typhi and Listeria monocytogenes, translates into relatively unchecked bacterial growth during the early phase of infection $[48,49]$. After this period of logarithmic growth, which has been demonstrated in rabbits, mice, and guinea pigs, the bacteria enter a relatively stationary phase [50]. During this critical time, $M t b$ subverts alveolar macrophage defenses, thereby ensuring prolonged intracellular survival and mycobacterial growth within this pulmonary niche.
Whether this failure of immunity represents an intrinsic deficiency of macrophages or an insufficient activation of macrophages by $\mathrm{T}$ cells remains uncertain [51].

As discussed above, there has been a proliferation of work with non-human primate models in recent years that shed further light on the establishment of the set point, particularly with regards to granuloma formation [52]. Studies of macaques with aerosol exposure to $M t b$ have found that early mycobacterial dissemination, as reflected by the development of new granulomas in the first 3-6 weeks following infection (i.e., the period during which the set point is established), is associated with subsequent progression to active disease $[53,54]$. Conversely, the absence of new granuloma formation, which could be construed as a "low" set point, is associated with immune control and long-term maintenance of latent infection. Granuloma size can also stratify the risk of dissemination, with larger granulomas associated with a greater potential for future mycobacterial spread [55]. By linking early immunologic events to clinically meaningful outcomes, these findings underscore the critical importance of early immune control prior to the onset of adaptive immunity. They also provide evidence to support the longstanding belief that progression to tuberculosis disease is determined at the level of the individual granuloma.

\section{Alveolar macrophage phenotypes in Mtb infection}

As the first cell type to encounter $M t b$, the alveolar macrophage is a key player in the early stages of infection and $M t b$ is known to both cause and benefit from certain alterations in macrophage functionality [56]. Several excellent reviews have recently examined the heterogeneity and plasticity of macrophages, in addition to proposing a uniform approach to macrophage nomenclature [31, 32]. Alveolar macrophages play myriad roles in the lungs, from housekeeper to innate immune effector, and their role depends heavily on the microenvironment within the alveolar space. For example, in response to inflammatory stimuli such as lipopolysaccharide (LPS), alveolar macrophages develop an inflammatory phenotype with increased production of cytokines such as TNF- $\alpha$ and IL-6. Conversely, in the setting of IL-4 exposure, alveolar macrophages shift to an immunosuppressive phenotype and increase production of regulatory cytokines such as TGF- $\beta$ [31]. Although debate continues as to how best to characterize macrophages and how dynamically tissue resident subtypes respond to their local cytokine milieu, it is well known that macrophages respond to different cytokine programs with a variety of functional changes. Most experts agree that these changes exist on a spectrum between the classically activated (or M1, or 
inflammatory) macrophage and an alternatively activated (or M2, or regulatory) macrophage.

In the context of $M t b$ infection, the "macrophage polarization ratio," an indicator of the balance between proinflammatory and anti-inflammatory genes, has been employed to explore how macrophage functionality and subsequent granuloma formation affects the probabilities of $M t b$ control and dissemination (Fig. 2) [57]. With this approach, NF-kB signaling was found to be an essential component of the classical activation profile, which, when triggered early, leads to improved clinical tuberculosis outcomes in a nonhuman primate model [57].

Alveolar macrophages are also severely impacted by the presence of HIV infection and have been shown to be a reservoir for the virus within the lungs [58]. Importantly, coinfection shifts macrophage polarization in a fashion favorable for pathogen survival [59]. Both HIV and $M t b$ stimulate a cytokine milieu in the alveolar space that pushes macrophages into an inflammatory phenotype optimized for the uptake of foreign microbes. Although these inflammatory cells would ordinarily excel at pathogen killing, the intracellular effects of HIV and $M t b$ render the macrophages less effective and, as a result, permit ongoing pathogen growth [60]. At the same time, there is ample evidence that $M t b$ infection of alveolar macrophages creates a permissive environment for HIV infection and replication, through a variety of mechanisms including increased surface expression of the HIV receptors
CCR5 and CXCR4, increased HIV transcription and replication, and induction of nanotubes that promote cell-to-cell HIV viral spread between macrophages [61-64]. Taken together, this synergy between $M t b$ - and HIV-mediated impacts on macrophages enables intracellular growth and survival of both pathogens and, more broadly, fuels the global syndemic of coinfection.

Macrophage function and polarization is also influenced by immunometabolism, the balance of cellular energy utilization. This represents another growing area of inquiry in which $M t b$ and HIV are likely to have complementary, yet deleterious, effects. Mtb infection of alveolar macrophages has been shown to shift cellular metabolism from oxidative phosphorylation to aerobic glycolysis, a shift associated with a more inflammatory, M1-like phenotype [65]. This shift triggers an increase in cellular IL- $1 \beta$ production along with a decrease in IL-10 production, which, in concert, should increase bacillary killing in vitro. Yet, other investigations suggest that persistence of fatty acid oxidation in alveolar macrophages may permit ongoing intracellular $M t b$ growth [66]. At the same time, HIV infection also alters cellular energy balance, oxidative stress levels, and mitochondrial bioenergetics, including for infected macrophages [67-70]. Further study of the combined, net effects of $M t b$ and HIV on alveolar macrophage immunometabolism is needed to expand our understanding of how coinfection impairs early mycobacterial control.
Early Mtb killing and control

- Pro-inflammatory phenotype and cytokines

- $\uparrow$ aerobic glycolysis

- $\uparrow$ GM-CSF:M-CSF ratio

- $\uparrow$ redox capacity

- $\uparrow$ Mtb recognition and phagocytosis

- $\uparrow$ phagolysosomal fusion

- $\uparrow$ apoptosis

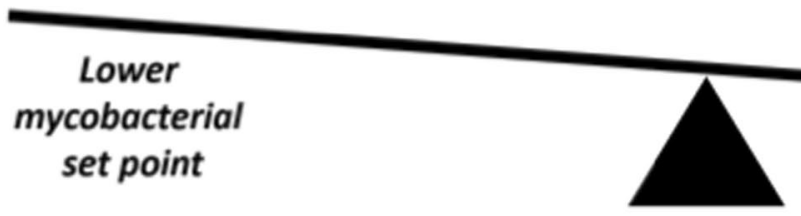

Early Mtb growth and dissemination

- Anti-inflammatory phenotype and cytokines

- $\uparrow$ oxidative phosphorylation

- $\downarrow$ GM-CSF:M-CSF ratio

- $\uparrow$ oxidative stress

- $\downarrow$ Mtb recognition and phagocytosis

- $\downarrow$ phagolysosomal fusion

- $\uparrow$ autophagy and necrosis infection

Fig. 2 The balance of alveolar macrophage polarization and activity. Early Mtb killing and control leads to a lower mycobacterial set point, whereas early Mtb growth and dissemination lead to a higher mycobacterial set point. HIV infection favors early Mtb growth and dissemination and a higher mycobacterial set point 


\section{Cytokine expression and innate immunity in Mtb and HIV}

Macrophage cytokine expression profiles may also vary according to the stage of $M t b$ infection, whereby the secreted protein ESAT-6 initially skews macrophages towards a M1 phenotype, potentially to facilitate the establishment of a granuloma, and then later to a more permissive M2 phenotype [71]. IFN- $\gamma$, a paradigmatic pro-inflammatory cytokine, drives macrophages towards an inflammatory phenotype and, under normal circumstances, is critical for $M t b$ control. However, peripheral blood mononuclear cells isolated from people with HIV have depressed IFN- $\gamma$ production in response to purified protein derivative (PPD) $[72,73]$. IL-4, another key cytokine for macrophage polarization, is induced by HIV glycoprotein (gp) 120 [74]. This induction shifts macrophages to an anti-inflammatory phenotype, potentially further reducing early $M t b$ control. In people without HIV, elevated IL-4 levels have been associated with progression to tuberculosis disease and the development of pulmonary cavities, thus underscoring the clinical impact of these shifts [75-77]. Interestingly, the relative balance of these cytokines may vary according to the stage of HIV infection, which could translate into differential susceptibility to and control of $M t b$ infection [60].

Several key cytokines important for both macrophage polarization and the response to $M t b$ are also altered in the presence of HIV coinfection. For example, GM-CSF plays an essential role in cellular control of $M t b[78,79]$ and its activity is impaired in monocyte-derived macrophages infected with HIV [80]. The GM-CSF:M-CSF balance is also altered by the presence of $M t b$ [81] and M-CSF-driven macrophages are more permissive to $M t b$ replication and dissemination [82]. Similarly, interleukin-1 receptor-associated kinase $M$ (IRAK-M), which is downstream of the GM-CSF-dependent transcription factor PU.1, correlates directly with mycobacterial load in human lung tissue and impacts $M t b$ survival [83]. Thus, the combined impact of $M t b$ and HIV on the balance of cytokines within the lungs leads to an environment that permits the growth of both pathogens.

\section{Alveolar macrophage oxidative stress in Mtb and HIV}

Another avenue ripe for further exploration is the effects of HIV and $M t b$ on redox systems, which can also modulate macrophage function [84-86]. HIV is known to impair antioxidant defenses in the alveolar macrophage and raise levels of oxidative stress in the lung more generally $[18,87]$. The effects in the lung are likely due, at least in part, to glutathione depletion in the airways of people with HIV $[88,89]$. Mtb, on the other hand, has successfully adapted to hostile intracellular conditions, including high oxidative stress $[90,91]$. Mtb may also directly contribute to oxidative stress by inducing heme oxygenase
(HO)-1, the levels of which directly correlate with treatment outcomes in people with active tuberculosis disease [92]. Several studies have demonstrated improved $M t b$ control with glutathione supplementation, including one study using macrophages isolated from people with HIV in which supplementation led to enhanced inflammatory cytokine production and restored macrophage capacity to control $M t b$ growth [89, 93-97]. Of note, the oxidative stress induced by Mtb-infected macrophages is also likely to promote HIV reactivation, further complicating the relationship between these two pathogens [98].

\section{Mtb recognition and phagocytosis by alveolar macrophages in HIV}

An important function of macrophages in the alveolar space is the differentiation of friend versus foe via pathogen recognition and phagocytosis (Fig. 3) [99-101]. Particularly germane to the recognition of $M t b$ is the mannose receptor, which is downregulated in people living with HIV [102]. HIV also leads to reduced expression and activity of toll-like receptors (TLR), another key receptor for macrophage pathogen recognition [103105]. When combined with shifts in TLR-mediated regulation of nitric oxide production induced by $M t b$ [104], these impairments have the potential to reduce $M t b$ uptake by alveolar macrophages and facilitate prolonged extracellular growth.

Once a pathogen like $M t b$ has been recognized, it then undergoes phagocytosis [99, 100]. HIV creates favorable conditions for bacteria by impairing phagocytosis of pathogens including Streptococcus [106]. The HIV protein Nef has also been shown to interfere with phagosome formation by impeding endosomal recruitment and remodeling [107]. Of note, impaired phagocytosis has been observed even in alveolar macrophages not directly infected by HIV $[58,108]$. While phagocytosis of $M t b$ in the setting of HIV has not specifically been studied, such impairments would enable further extracellular growth $[18,109]$.

HIV has also been found in macrophage endosomes and is known to impair phagolysosomal fusion in the macrophage [110, 111]. At least some of these impairments may be mediated through the effects of the HIVrelated protein transactivator of transcription (Tat) [112]. Another HIV protein, Vpr, has also been shown to perturb phagolysosomal maturation by altering microtubule-dependent trafficking within macrophages [113]. In addition, HIV has been shown to co-opt the Rag GTPases, resulting in further disruption of endosomal trafficking [114]. This disruption may facilitate HIV replication and simultaneously assist $M t b$ evasion of lysosomal fusion and killing. IL-10 has also been shown to dysregulate the response to $M t b$ in the setting of HIV, at 


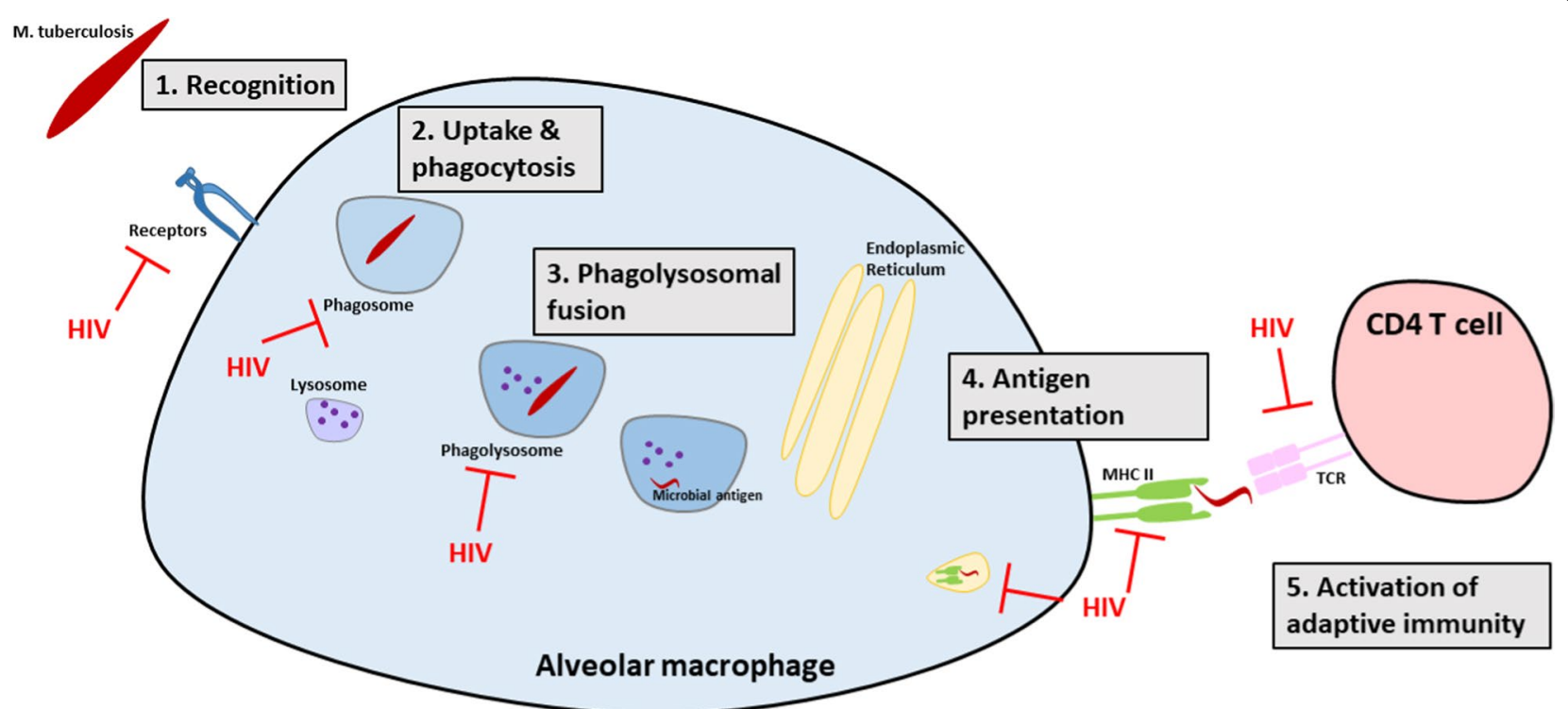

Fig. 3 Events in alveolar macrophage uptake and response to Mtb infection that are impacted by HIV coinfection. (1) Recognition: HIV coinfection downregulates alveolar macrophage expression of Mtb recognition receptors including mannose and toll-like receptors. (2) Uptake and phagocytosis: HIV coinfection impairs phagocytosis. (3) Phagolysosomal fusion: HIV coinfection disrupts endosomal trafficking and impairs phagolysosomal maturation. (4) Antigen presentation: HIV coinfection leads to the expression of immature MHC class II complexes and thereby impairs the activation of adaptive immune responses. (5) Activation of adaptive immunity: HIV coinfection reduces the expression of costimulatory molecules for activation of adaptive immunity. The net effect of these HIV-mediated impairments is to enable increased intracellular and extracellular Mtb growth which ultimately leads to a higher mycobacterial set point

least in part by impairing phagosome maturation $[115$, 116]. However, in one study of alveolar macrophages from humans with active tuberculosis disease, phagolysosomal acidification was equally disrupted among those with and without HIV, highlighting existing uncertainties about the impacts of $M t b$ and HIV on alveolar macrophage phagocytosis [117]. Thus, although further research is needed to define the relevant mechanisms by which HIV impairs the phagocytic response to $M t b$, the bulk of the existing data suggest that endosomes fail to fuse with acidified lysosomes, thereby promoting $M t b$ survival [118].

\section{Cell death pathways in Mtb-HIV infected macrophages}

Alveolar macrophage cell death pathways range from apoptosis to autophagy and necrosis. $M t b$ is known to shift the balance toward necrosis by actively inhibiting apoptosis, thereby allowing the extracellular release of viable mycobacteria from dying alveolar macrophages $[119,120]$. Similarly, HIV, via the viral proteins Tat and glycoprotein-120 (gp-120), stimulates the triggering receptor expressed on myeloid cells-1 (TREM-1), thereby inhibiting apoptosis in a p65-dependent manner [121]. HIV may also directly induce autophagy through the Nef protein, in order to modulate viral replication and survival, albeit in a manner that may be synergistic with
Mtb-mediated inhibition of apoptosis [122, 123]. Gp-120 also impairs apoptosis-associated killing of pneumococcus within alveolar macrophages, indicating that this impairment may not be specific to $M t b$ [124]. Impaired apoptosis of $M t b$ has been tied by other investigators to IL-10, which is increased in the bronchoalveolar lavage fluid of people with HIV [125]. Additional research is needed to further delineate the impact of these shifts in cell death pathways and to identify whether there are therapeutic opportunities to improve $M t b$ control in patients with and without HIV. One promising recent report found that all-trans retinoic acid was able to promote autophagy of human alveolar macrophages in the setting of $M t b$ infection [126].

\section{Activation of adaptive immunity in Mtb-HIV coinfection}

The final step required for establishment of the mycobacterial set point is activation of the adaptive arm of the immune system (Fig. 3). $M t b$ has been shown to delay the activation of adaptive immunity in mice by slowing bacterial transport to local lymph nodes [46]. This delay allows for a prolonged period of unchecked bacterial growth within the lungs, with a 10,000-100,000-fold expansion of the $M t b$ pulmonary population during this time. At least one driver of this delay is $M t b$-mediated inhibition of MHC class II antigen presentation by dendritic 
cells [127]. $M t b$ also manipulates antigen presentation by diverting bacterial proteins through a vesicular export pathway, away from MHC class II presentation. In the context of HIV, the viral protein Nef has been shown to promote the expression of immature, functionally incompetent MHC class II complexes [128, 129]. Recent data have more directly linked these two by demonstrating that HIV-infected dendritic cells have reduced ability to upregulate key costimulatory molecules critical for antigen presentation (e.g., CD40, CD80, and CD86) in the presence of $M t b$ infection [130]. All of this would combine to delay the onset of adapative immunity and further increase the mycobacterial set point.

\section{Net effects: the combined immunologic consequences of coinfection with Mtb and HIV}

As should be clear from the preceding sections, studies detailing the effects of $M t b$ and HIV on the immune responses within the alveolar space have found an abundance of affected cytokines, pathways, and response elements. Although much of the available data suggests ways in which $M t b$ and HIV each make it more likely for the other to gain ground within an individual's lungs, the myriad as-yet-unstudied pathways leave open the distinct possibility that some of their particular effects may cumulatively cancel out those of the other pathogen. It is in this key domain that we believe the concept of a mycobacterial set point most clearly demonstrates its worth. Because the set point relates to the mycobacterial burden at the moment in which the adaptive immune system activates, it offers a clinically relevant marker that synthesizes the various effects of coinfections, comorbidities, and therapeutics. As a research tool, then, it will help us understand whether the net effect of a given intervention actually reduces the overall mycobacterial burden, as opposed to fruitfully manipulating a single pathway (with the knowledge that doing so may have deleterious effects on others).

\section{Measuring the mycobacterial set point in human infection and disease}

Fortunately, several novel approaches provide hope for expanding our understanding of these early immunologic events in humans. These tools have the potential to vastly enhance our current knowledge by quantifying the functional impact of coinfection on bacterial burden and early human immune responses, while also offering insight into mechanisms underlying early immune control or escape.

The first such tool is 2-deoxy-2-[18F]fluoro-D-glucose ([18F]FDG) positron emission tomography combined with computed tomography (PET-CT), which identifies areas of increased cellular metabolic activity as would occur with an immune response to infection. Several macaque studies have leveraged PET-CT imaging to gain insight into early infection by following the progression of individual granulomas after aerosol infection [53, $54,131,132]$. PET-CT has also been employed to study tuberculosis in humans, including a cohort of 35 people with HIV and latent tuberculosis infection, 10 of whom had PET-avid lesions suspicious for subclinical disease [133]. Those with PET activity were significantly more likely to develop active tuberculosis disease during the following 6 months, suggesting metabolic activity on PET imaging may be able to identify patients with ineffective early immune responses to $M t b$ infection.

Blood-based immunologic signatures represent another potential avenue for studying early infection. Recent studies in macaques and humans have identified RNA signatures predictive of progression to active tuberculosis disease [134-136]. Notably, the macaque signature was predictive just 3-6 weeks after aerosol infection, providing compelling evidence for the value of these signatures even very early in infection. This signature also identified a novel gene in tuberculosis pathogenesis, $P R D X 2$, a member of the reactive oxygen species scavenger system. Further studies are warranted to explore the role of $P R D X 2$ in early infection, and how that response may be skewed by HIV and other known tuberculosis risk factors. Similarly, characterization of $M t b$-specific $\mathrm{T}$ cell responses may provide another means for understanding adaptive immune responses important in early infection. In a recent report of a whole blood assay of $\mathrm{T}$ cell responses to $60 \mathrm{Mtb}$ antigens, immunogenic $\mathrm{Mtb}$ antigens were successfully identified across a diverse range of populations and infectious states [137]. Longitudinal studies are underway to determine if these $T$ cell signatures correlate with early immune responses-both those that clear infection and those that permit ongoing $M t b$ growth and dissemination.

Yet another tool for identifying and studying early infection is plasma metabolomics, in which small molecules are identified using high-resolution mass spectrometry. This approach has been successfully employed to identify direct metabolites of $M t b$, and may be able to identify low levels even early in infection. Metabolomics has also been used to identify distinct signatures of the host immune response, whereby investigators were able to distinguish between risk-associated metabolites associated with a higher likelihood of progression to tuberculosis disease and disease-associated metabolites that increased in a time-dependent manner among those with progression to active tuberculosis disease [138-140]. Looking ahead, it will be important to determine whether these metabolic signatures are similarly predictive and valid in people with HIV. 


\section{Conclusion}

Across the scientific community, there is overwhelming consensus over the need to understand protective immunity to $M t b$ [55]. As a framework for considering early immunologic responses to $M t b$, the mycobacterial set point provides a useful construct for understanding the impact of early immune control and clinical outcomes of tuberculosis. Given the disproportionate burden of tuberculosis disease and deaths among people with HIV despite widespread ART [23], it is imperative to study the unique impacts of HIV on $M t b$ infection and susceptibility. To date, research evaluating the effects of HIV on the alveolar macrophage response to $M t b$ has been relatively limited, particularly with regard to the critical early events that help to dictate the mycobacterial set point. While we believe that a higher mycobacterial set point is a key contributor to the increased morbidity among people with HIV, additional research is needed to better understand the mechanisms and biological pathways that may be involved in facilitating mycobacterial immune evasion. A greater understanding of the impact of HIV on these earliest responses to $M t b$ may lead to the development of novel interventions and hostdirected therapies to reduce the persistent global burden of tuberculosis in this vulnerable population.

\section{Acknowledgements}

We would like to thank our colleague Cheryl L. Day, PhD, for review, thoughtful discussion, and feedback on this manuscript.

\section{Authors' contributions}

SCA and BSS conceived of the review, drafted and revised the manuscript. Both authors read and approved the final manuscript.

\section{Funding}

This work was supported by the following grants: NIH/NIAID K23 Al134182 (Auld), NIH/NIAAA K08 AA024512 (Staitieh), the Emory Center for AIDS Research (P30AI050409).

\section{Availability of data and materials \\ Not applicable.}

Ethics approval and consent to participate

Not applicable.

\section{Consent for publication}

Not applicable.

\section{Competing interests}

The authors declare that they have no competing interests.

\section{Author details}

${ }^{1}$ Emory University School of Medicine, Atlanta, GA, USA. ${ }^{2}$ Rollins School of Public Health, Emory University, Atlanta, GA, USA.

Received: 10 July 2020 Accepted: 15 September 2020

Published online: 23 September 2020

\footnotetext{
References

1. Murray JF, Schraufnagel DE, Hopewell PC. Treatment of tuberculosis. A historical perspective. Ann Am Thoracic Soc. 2015;12(12):1749-59.
}

2. Bayer R, Wilkinson D. Directly observed therapy for tuberculosis: history of an idea. Lancet. 1995;345(8964):1545-8.

3. Enarson DA. Principles of IUATLD collaborative tuberculosis progammes. Bull Int Union Against Tuberc Lung Dis. 1991;66(4):195-200.

4. Iseman MD. Tuberculosis therapy: past, present and future. Eur Respir J. 2002;20(36 suppl):87S-94s.

5. Centers for Disease Control. Pneumocystis pneumonia-Los Angeles. MMWR Morb Mortal Wkly Rep. 1981;30(21):250-2.

6. Global Tuberculosis Report. In.: WHO; 2017.

7. Kwan CK, Ernst JD. HIV and tuberculosis: a deadly human syndemic. Clin Microbiol Rev. 2011;24(2):351-76.

8. Pai M, Behr MA, Dowdy D, Dheda K, Divangahi M, Boehme CC, Ginsberg A, Swaminathan S, Spigelman M, Getahun H, et al. Tuberculosis. Nat Rev Dis Primers. 2016:2:16076.

9. Cadena AM, Flynn JL, Fortune SM. The importance of first impressions: early events in Mycobacterium tuberculosis infection influence outcome. mBio. 2016;7(2):e00342-00316.

10. Lefrere JJ, Roudot-Thoraval F, Mariotti M, Thauvin M, Lerable J, Salpetrier $J$, Morand-Joubert $L$. The risk of disease progression is determined during the first year of human immunodeficiency virus type 1 infection. J Infect Dis. 1998;177(6):1541-8.

11. Sterling TR, Vlahov D, Astemborski J, Hoover DR, Margolick JB, Quinn TC. Initial plasma HIV-1 RNA levels and progression to AIDS in women and men. N Engl J Med. 2001;344(10):720-5.

12. Fellay J, Shianna KV, Ge D, Colombo S, Ledergerber B, Weale M, Zhang K, Gumbs C, Castagna A, Cossarizza A, et al. A whole-genome association study of major determinants for host control of HIV-1. Science. 2007;317(5840):944-7.

13. Mackelprang RD, Carrington M, Thomas KK, Hughes JP, Baeten JM, Wald A, Farquhar C, Fife K, Campbell MS, Kapiga S, et al. Host genetic and viral determinants of HIV-1 RNA set point among HIV-1 seroconverters from Sub-Saharan Africa. J Virol. 2015;89(4):2104-11.

14. Bartha I, McLaren PJ, Brumme C, Harrigan R, Telenti A, Fellay J. Estimating the respective contributions of human and viral genetic variation to HIV control. PLoS Comput Biol. 2017;13(2):e1005339.

15. Srivastava S, Ernst JD, Desvignes L. Beyond macrophages: the diversity of mononuclear cells in tuberculosis. Immunol Rev. 2014;262(1):179-92.

16. Cohen SB, Gern BH, Delahaye JL, Adams KN, Plumlee CR, Winkler JK, Sherman DR, Gerner MY, Urdahl KB. Alveolar macrophages provide an early Mycobacterium tuberculosis niche and initiate dissemination. Cell Host Microbe. 2018;24(3):439-446.e434.

17. Ernst JD. Mechanisms of M. tuberculosis immune evasion as challenges to TB vaccine design. Cell Host Microbe. 2018;24(1):34-42.

18. Staitieh BS, Egea EE, Guidot DM. Pulmonary innate immune dysfunction in human immunodeficiency virus. Am J Respir Cell Mol Biol. 2017;56(5):563-7.

19. Centers for Disease Control and Prevention. Multidrug-resistant tuberculosis outbreak on an HIV ward-Madrid, Spain, 1991-1995. MMWR Morb Mortal Wkly Rep. 1996;45(16):330-3.

20. Centers for Disease Control and Prevention. Nosocomial transmission of multidrug-resistant tuberculosis among HIV-infected personsFlorida and New York, 1988-1991. MMWR Morb Mortal Wkly Rep. 1991:40(34):585-91.

21. Moro ML, Gori A, Errante I, Infuso A, Franzetti F, Sodano L, lemoli E. An outbreak of multidrug-resistant tuberculosis involving HIV-infected patients of two hospitals in Milan, Italy. Italian Multidrug-Resistant Tuberculosis Outbreak Study Group. Aids. 1998;12(9):1095-102.

22. Sonnenberg P, Glynn JR, Fielding K, Murray J, Godfrey-Faussett P, Shearer S. How soon after infection with HIV does the risk of tuberculosis start to increase? A retrospective cohort study in South African gold miners. J Infect Dis. 2005;191(2):150-8.

23. Gupta A, Wood R, Kaplan R, Bekker LG, Lawn SD. Tuberculosis incidence rates during 8 years of follow-up of an antiretroviral treatment cohort in South Africa: comparison with rates in the community. PLoS ONE. 2012;7(3):e34156.

24. Girardi E, Antonucci G, Vanacore P, Palmieri F, Matteelli A, lemoli E, Carradori S, Salassa B, Pasticci MB, Raviglione MC, et al. Tuberculosis in $\mathrm{HIV}$-infected persons in the context of wide availability of highly active antiretroviral therapy. Eur Respir J. 2004;24(1):11-7.

25. Williams A, Orme IM. Animal models of tuberculosis: an overview. Microbiol Spectrum. 2016:4(4):131-42 
26. Helke KL, Mankowski JL, Manabe YC. Animal models of cavitation in pulmonary tuberculosis. Tuberculosis. 2006;86(5):337-48.

27. Keiser TL, Purdy GE. Killing Mycobacterium tuberculosis in vitro: what model systems can teach us. Microbiol Spectrum. 2017;5(3):541-56.

28. Bogdan C. Nitric oxide synthase in innate and adaptive immunity: an update. Trends Immunol. 2015;36(3):161-78.

29. Zinman G, Brower-Sinning R, Emeche CH, Ernst J, Huang GT, Mahony S, Myers AJ, O'Dee DM, Flynn JL, Nau GJ, et al. Large scale comparison of innate responses to viral and bacterial pathogens in mouse and macaque. PLoS ONE. 2011;6(7):e22401.

30. Ginhoux F, Guilliams M. Tissue-resident macrophage ontogeny and homeostasis. Immunity. 2016;44(3):439-49.

31. Murray PJ, Allen JE, Biswas SK, Fisher EA, Gilroy DW, Goerdt S, Gordon S, Hamilton JA, Ivashkiv LB, Lawrence T, et al. Macrophage activation and polarization: nomenclature and experimental guidelines. Immunity. 2014:41(1):14-20.

32. Gordon S, Plüddemann A, Martinez Estrada F. Macrophage heterogeneity in tissues: phenotypic diversity and functions. Immunol Rev. 2014;262(1):36-55.

33. Redente EF, Higgins DM, Dwyer-Nield LD, Orme IM, Gonzalez-Juarrero M, Malkinson AM. Differential polarization of alveolar macrophages and bone marrow-derived monocytes following chemically and pathogeninduced chronic lung inflammation. J Leukoc Biol. 2010;88(1):159-68.

34. Schwander S, Dheda K. Human lung immunity against Mycobacterium tuberculosis: insights into pathogenesis and protection. Am J Respir Crit Care Med. 2011;183(6):696-707.

35. Bouz G, Al Hasawi N. The zebrafish model of tuberculosis-no lungs needed. Crit Rev Microbiol. 2018;44(6):779-92.

36. Cooper AM. Mouse model of tuberculosis. Cold Spring Harbor Perspect Med. 2014;5(2):a018556

37. Singh AK, Gupta UD. Animal models of tuberculosis: lesson learnt. Indian J Med Res. 2018;147(5):456-63.

38. Datta M, Via LE, Kamoun WS, Liu C, Chen W, Seano G, Weiner DM, Schimel D, England K, Martin JD, et al. Anti-vascular endothelial growth factor treatment normalizes tuberculosis granuloma vasculature and improves small molecule delivery. Proc Natl Acad Sci USA. 2015;112(6):1827-32.

39. Darrah PA, Zeppa JJ, Maiello P, Hackney JA, Wadsworth MH 2nd, Hughes TK, Pokkali S, Swanson PA 2nd, Grant NL, Rodgers MA, et al. Prevention of tuberculosis in macaques after intravenous BCG immunization. Nature. 2020;577(7788):95-102.

40. Peña JC, Ho W-Z. Monkey models of tuberculosis: lessons learned. Infect Immun. 2015;83(3):852-62.

41. Poulsen A. Some clinical features of tuberculosis. 1. Incubation period. Acta tuberculosea Scandinavica. 1950;24(3-4):311-46.

42. Gedde-Dahl T. Tuberculous infection in the light of tuberculin matriculation. Am J Hygiene. 1952;56(2):139-214.

43. Wallgren A. The time-table of tuberculosis. Tubercle. 1948;29(11):245-51.

44. Lurie MB. Resistance to tuberculosis: experimental studies in native and acquired defensive mechanism. Cambridge: Harvard University Press; 1964.

45. Smith DW, Harding GE. Animal model of human disease. Pulmonary tuberculosis. Animal model: experimental airborne tuberculosis in the guinea pig. Am J Pathol. 1977;89(1):273-6.

46. Wolf AJ, Desvignes L, Linas B, Banaiee N, Tamura T, Takatsu K, Ernst JD. Initiation of the adaptive immune response to Mycobacterium tuberculosis depends on antigen production in the local lymph node, not the lungs. J Exp Med. 2008;205(1):105-15.

47. Dannenberg AM Jr. Delayed-type hypersensitivity and cell-mediated immunity in the pathogenesis of tuberculosis. Immunol Today. 1991;12(7):228-33.

48. McSorley SJ, Asch S, Costalonga M, Reinhardt RL, Jenkins MK. Tracking salmonella-specific CD4 T cells in vivo reveals a local mucosal response to a disseminated infection. Immunity. 2002;16(3):365-77.

49. Kursar M, Bonhagen K, Kohler A, Kamradt T, Kaufmann SH, Mittrucker HW. Organ-specific CD4+T cell response during Listeria monocytogenes infection. J Immunol. 2002;168(12):6382-7.

50. Dannenberg AM Jr, Collins FM. Progressive pulmonary tuberculosis is not due to increasing numbers of viable bacilli in rabbits, mice and guinea pigs, but is due to a continuous host response to mycobacterial products. Tuberculosis (Edinb). 2001;81(3):229-42.

51. North RJ, Jung YJ. Immunity to tuberculosis. Annu Rev Immunol. 2004;22:599-623.

52. Capuano SV, Croix DA, Pawar S, Zinovik A, Myers A, Lin PL, Bissel S, Fuhrman C, Klein E, Flynn JL. Experimental Mycobacterium tuberculosis infection of cynomolgus macaques closely resembles the various manifestations of human M. tuberculosis infection. Infect Immun. 2003;71(10):5831-44

53. Coleman MT, Maiello P, Tomko J, Frye LJ, Fillmore D, Janssen C, Klein E, Lin PL. Early Changes by (18)Fluorodeoxyglucose positron emission tomography coregistered with computed tomography predict outcome after Mycobacterium tuberculosis infection in cynomolgus macaques. Infect Immun. 2014;82(6):2400-4.

54. Martin CJ, Cadena AM, Leung VW, Lin PL, Maiello P, Hicks N, Chase MR, Flynn JL, Fortune SM. Digitally barcoding Mycobacterium tuberculosis reveals in vivo infection dynamics in the macaque model of tuberculosis. mBio. 2017;8(3):e00312-17.

55. Huang L, Russell DG. Protective immunity against tuberculosis: what does it look like and how do we find it? Curr Opin Immunol. 2017:48:44-50.

56. Antonelli LR, Gigliotti Rothfuchs A, Goncalves R, Roffe E, Cheever AW, Bafica A, Salazar AM, Feng CG, Sher A. Intranasal Poly-IC treatment exacerbates tuberculosis in mice through the pulmonary recruitment of a pathogen-permissive monocyte/macrophage population. J Clin Invest. 2010;120(5):1674-82.

57. Marino S, Cilfone NA, Mattila JT, Linderman JJ, Flynn JL, Kirschner DE. Macrophage polarization drives granuloma outcome during Mycobacterium tuberculosis infection. Infect Immun. 2015;83(1):324-38.

58. Cribbs SK, Lennox J, Caliendo AM, Brown LA, Guidot DM. Healthy HIV-1-infected individuals on highly active antiretroviral therapy harbor HIV-1 in their alveolar macrophages. AIDS Res Hum Retroviruses. 2015;31(1):64-70.

59. Lugo-Villarino G, Verollet C, Maridonneau-Parini I, Neyrolles O. Macrophage polarization: convergence point targeted by mycobacterium tuberculosis and HIV. Front Immunol. 2011;2:43.

60. Herbein $\mathrm{G}$, Varin A. The macrophage in HIV-1 infection: from activation to deactivation? Retrovirology. 2010;7:33-33.

61. Souriant S, Balboa L, Dupont M, Pingris K, Kviatcovsky D, Cougoule C, Lastrucci C, Bah A, Gasser R, Poincloux R, et al. Tuberculosis exacerbates HIV-1 infection through IL-10/STAT3-dependent tunneling nanotube formation in macrophages. Cell Rep. 2019:26(13):3586-3599.e3587.

62. Kuroda MJ, Sugimoto C, Cai Y, Merino KM, Mehra S, Araínga M, Roy CJ, Midkiff CC, Alvarez X, Didier ES, et al. High turnover of tissue macrophages contributes to tuberculosis reactivation in simian immunodeficiency virus-infected rhesus macaques. J Infect Dis. 2018;217(12):1865-74.

63. Khan N, Divangahi M. Mycobacterium tuberculosis and HIV coinfection brings fire and fury to macrophages. J Infect Dis. 2018;217(12):1851-3.

64. Waters R, Ndengane M, Abrahams M-R, Diedrich CR, Wilkinson RJ, Coussens AK. The Mtb-HIV syndemic interaction: why treating $M$. tuberculosis infection may be crucial for HIV-1 eradication. Fut Virol. 2020:15(2):101-26.

65. Gleeson LE, Sheedy FJ, Palsson-McDermott EM, Triglia D, O'Leary SM, O'Sullivan MP, O'Neill LA, Keane J. Cutting edge: Mycobacterium tuberculosis induces aerobic glycolysis in human alveolar macrophages that is required for control of intracellular bacillary replication. J Immunol. 2016;196(6):2444-9.

66. Huang L, Nazarova EV, Tan S, Liu Y, Russell DG. Growth of Mycobacterium tuberculosis in vivo segregates with host macrophage metabolism and ontogeny. J Exp Med. 2018;215(4):1135-52.

67. Palmer CS, Henstridge DC, Yu D, Singh A, Balderson B, Duette G, Cherry $\mathrm{CL}$, Anzinger JJ, Ostrowski M, Crowe SM. Emerging role and characterization of immunometabolism: relevance to HIV pathogenesis. Serious Non-AIDS Events Cure. 2016;196(11):4437-44.

68. Rodriguez-Mora S, Mateos E, Moran M, Martin MA, Lopez JA, Calvo E, Terron MC, Luque D, Muriaux D, Alcami J, et al. Intracellular expression of Tat alters mitochondrial functions in T cells: a potential mechanism to understand mitochondrial damage during HIV-1 replication. Retrovirology. 2015;12:78 
69. Auld SC, Fernandes J, Ahmed M, Gandhi NR, Yeligar SM, Staitieh BS. Abnormal immunometabolism and gene accessibility in alveolar macrophages in HIV. In: Conference on retroviruses and opportunistic infections (CROI): 2020; Boston, MA; 2020.

70. Castellano P, Prevedel L, Valdebenito S, Eugenin EA. HIV infection and latency induce a unique metabolic signature in human macrophages. Sci Rep. 2019;9(1):3941.

71. Refai A, Gritli S, Barbouche MR, Essafi M. Mycobacterium tuberculosis virulent factor ESAT-6 drives macrophage differentiation toward the pro-inflammatory $\mathrm{M} 1$ phenotype and subsequently switches it to the anti-inflammatory M2 phenotype. Front Cell Infect Microbiol. 2018;8:327.

72. Hirsch CS, Toossi Z, Othieno C, Johnson JL, Schwander SK, Robertson S, Wallis RS, Edmonds K, Okwera A, Mugerwa R, et al. Depressed T-cell interferon-gamma responses in pulmonary tuberculosis: analysis of underlying mechanisms and modulation with therapy. J Infect Dis. 1999;180(6):2069-73.

73. Roff SR, Noon-Song EN, Yamamoto JK. The significance of interferon- $Y$ in HIV-1 pathogenesis, therapy, and prophylaxis. Front Immunol. 2014:4:498-498

74. Patella V, Florio G, Petraroli A, Marone G. HIV-1 gp120 Induces IL-4 and $\mathrm{IL}-13$ release from human $\mathrm{FccRI}^{+}$cells through interaction with the $\mathrm{V}_{\mathrm{H}} 3$ region of IgE. J Immunol. 2000;164(2):589-95.

75. Hussain R, Talat N, Ansari A, Shahid F, Hasan Z, Dawood G. Endogenously activated interleukin-4 differentiates disease progressors and non-progressors in tuberculosis susceptible families: a 2-year biomarkers follow-up study. J Clin Immunol. 2011;31(5):913-23.

76. Ordway DJ, Costa L, Martins M, Silveira H, Amaral L, Arroz MJ, Ventura FA, Dockrell HM. Increased Interleukin-4 production by CD8 and gammadelta T cells in health-care workers is associated with the subsequent development of active tuberculosis. J Infect Dis. 2004;190(4):756-66

77. van Crevel R, Karyadi E, Preyers F, Leenders M, Kullberg BJ, Nelwan RH, van der Meer JW. Increased production of interleukin 4 by CD4+and $\mathrm{CD} 8+\mathrm{T}$ cells from patients with tuberculosis is related to the presence of pulmonary cavities. J Infect Dis. 2000;181(3):1194-7.

78. Rothchild AC, Stowell B, Goyal G, Nunes-Alves C, Yang Q, Papavinasasundaram K, Sassetti CM, Dranoff G, Chen X, Lee J, et al. Role of granulocyte-macrophage colony-stimulating factor production by $T$ cells during Mycobacterium tuberculosis infection. mBio. 2017. https:// doi.org/10.1128/mbio.01514-17.

79. Chroneos ZCJ, C. Immunoregulatory role of GM-CSF in pulmonary tuberculosis. In: Cardona PJ, editor. Understanding tuberculosis-analyzing the origin of Mycobacterium tuberculosis pathogenicity; 2012.

80. Warby TJ, Crowe SM, Jaworowski A. Human immunodeficiency virus type 1 infection inhibits granulocyte-macrophage colony-stimulating factor-induced activation of STAT5A in human monocyte-derived macrophages. J Virol. 2003;77(23):12630-8.

81. Higgins DM, Sanchez-Campillo J, Rosas-Taraco AG, Higgins JR, Lee EJ, Orme IM, Gonzalez-Juarrero M. Relative levels of M-CSF and GM-CSF influence the specific generation of macrophage populations during infection with Mycobacterium tuberculosis. J Immunol. 2008:180(7):4892-900.

82. Lerner TR, Borel S, Greenwood DJ, Repnik U, Russell MR, Herbst S, Jones ML, Collinson LM, Griffiths G, Gutierrez MG. Mycobacterium tuberculosis replicates within necrotic human macrophages. J Cell Biol. 2017;216(3):583-94

83. Shen P, Li Q, Ma J, Tian M, Hong F, Zhai X, Li J, Huang H, Shi C. IRAK-M alters the polarity of macrophages to facilitate the survival of Mycobacterium tuberculosis. BMC Microbiol. 2017;17(1):185.

84. Morris D, Khurasany M, Nguyen T, Kim J, Guilford F, Mehta R, Gray D, Saviola B, Venketaraman V. Glutathione and infection. Biochem Biophys Acta. 2013;1830(5):3329-49.

85. Allen M, Bailey C, Cahatol I, Dodge L, Yim J, Kassissa C, Luong J, Kasko S, Pandya S, Venketaraman V. Mechanisms of control of Mycobacterium tuberculosis by NK cells: role of glutathione. Front Immunol. 2015:6:508.

86. Peterson JD, Herzenberg LA, Vasquez K, Waltenbaugh C. Glutathione levels in antigen-presenting cells modulate Th1 versus Th2 response patterns. Proc Natl Acad Sci USA. 1998;95(6):3071-6.

87. Ivanov AV, Valuev-Elliston VT, Ivanova ON, Kochetkov SN, Starodubova ES, Bartosch B, Isaguliants MG. Oxidative stress during HIV infection: mechanisms and consequences. Oxid Med Cell Longev. 2016;2016:8910396.

88. Cribbs SK, Guidot DM, Martin GS, Lennox J, Brown LA. Anti-retrovira therapy is associated with decreased alveolar glutathione levels even in healthy HIV-infected individuals. PLoS ONE. 2014;9(2):e88630.

89. Morris D, Guerra C, Khurasany M, Guilford F, Saviola B, Huang Y, Venketaraman V. Glutathione supplementation improves macrophage functions in HIV. J Interferon Cytokine Res. 2013;33(5):270-9.

90. Singh A, Crossman DK, Mai D, Guidry L, Voskuil MI, Renfrow MB, Steyn AJ. Mycobacterium tuberculosis WhiB3 maintains redox homeostasis by regulating virulence lipid anabolism to modulate macrophage response. PLoS Pathog. 2009;5(8):e1000545.

91. Trivedi A, Singh N, Bhat SA, Gupta P, Kumar A. Redox biology of tuberculosis pathogenesis. Adv Microb Physiol. 2012;60:263-324.

92. Rockwood N, Costa DL, Amaral EP, Du Bruyn E, Kubler A, Gil-Santana L, Fukutani KF, Scanga CA, Flynn JL, Jackson SH, et al. Mycobacterium tuberculosis induction of heme oxygenase-1 expression is dependent on oxidative stress and reflects treatment outcomes. Front Immunol. 2017:8:542.

93. Alam K, Ghousunnissa S, Nair S, Valluri VL, Mukhopadhyay S. Glutathione-redox balance regulates c-rel-driven IL-12 production in macrophages: possible implications in antituberculosis immunotherapy. J Immunol. 2010;184(6):2918-29.

94. Palanisamy GS, Kirk NM, Ackart DF, Shanley CA, Orme IM, Basaraba RJ. Evidence for oxidative stress and defective antioxidant response in guinea pigs with tuberculosis. PLoS ONE. 2011;6(10):e26254.

95. Venketaraman V, Millman A, Salman M, Swaminathan S, Goetz M Lardizabal A, David H, Connell ND. Glutathione levels and immune responses in tuberculosis patients. Microb Pathog. 2008:44(3):255-61.

96. Ly J, Lagman M, Saing T, Singh MK, Tudela EV, Morris D, Anderson J, Daliva J, Ochoa C, Patel N, et al. Liposomal glutathione supplementation restores TH1 cytokine response to Mycobacterium tuberculosis infection in HIV-infected individuals. J Interferon Cytokine Res. 2015;35(11):875-87.

97. Guerra C, Morris D, Sipin A, Kung S, Franklin M, Gray D, Tanzil M, Guilford F, Khasawneh FT, Venketaraman V. Glutathione and adaptive immune responses against Mycobacterium tuberculosis infection in healthy and HIV infected individuals. PLOS ONE. 2011:6(12):e28378.

98. Tyagi P, Pal VK, Agrawal R, Singh S, Srinivasan S, Singh A. Mycobacterium tuberculosis reactivates HIV-1 via exosome-mediated resetting of cellular redox potential and bioenergetics. mBio. 2020. https://doi. org/10.1128/mBio.03293-19.

99. Luzio JP, Parkinson MD, Gray SR, Bright NA. The delivery of endocytosed cargo to lysosomes. Biochem Soc Trans. 2009;37(Pt 5):1019-21.

100. Luzio JP, Gray SR, Bright NA. Endosome-lysosome fusion. Biochem Soc Trans. 2010;38(6):1413-6.

101. Zhang C, Yang L, Zhao N, Zhao Y, Shi C. Insights into macrophage autophagy in latent tuberculosis infection: role of heat shock protein 16.3. DNA Cell Biol. 2018;37(5):442-8.

102. Koziel H, Eichbaum Q, Kruskal BA, Pinkston P, Rogers RA, Armstrong MY, Richards FF, Rose RM, Ezekowitz RA. Reduced binding and phagocytosis of Pneumocystis carinii by alveolar macrophages from persons infected with HIV-1 correlates with mannose receptor downregulation. J Clin Invest. 1998;102(7):1332-44.

103. Richardson ET, Shukla S, Sweet DR, Wearsch PA, Tsichlis PN, Boom WH, Harding CV. Toll-like receptor 2-dependent extracellular signalregulated kinase signaling in Mycobacterium tuberculosis-infected macrophages drives anti-inflammatory responses and inhibits Th1 polarization of responding T cells. Infect Immun. 2015;83(6):2242-54.

104. El Kasmi KC, Qualls JE, Pesce JT, Smith AM, Thompson RW, HenaoTamayo M, Basaraba RJ, Konig T, Schleicher U, Koo MS, et al. Toll-like receptor-induced arginase 1 in macrophages thwarts effective immunity against intracellular pathogens. Nat Immunol. 2008;9(12):1399-406.

105. Nicol MQ, Mathys JM, Pereira A, Ollington $\mathrm{K}$, leong MH, Skolnik PR. Human immunodeficiency virus infection alters tumor necrosis factor alpha production via Toll-like receptor-dependent pathways in alveolar macrophages and U1 cells. J Virol. 2008;82(16):7790-8.

106. Gordon SB, Jagoe RT, Jarman ER, North JC, Pridmore A, Musaya J, French $\mathrm{N}$, Zijlstra EE, Molyneux ME, Read RC. The alveolar microenvironment of patients infected with human immunodeficiency virus does not modify 
alveolar macrophage interactions with Streptococcus pneumoniae. Clin Vaccine Immunol. 2013;20(6):882-91.

107. Mazzolini J, Herit F, Bouchet J, Benmerah A, Benichou S, Niedergang F. Inhibition of phagocytosis in HIV-1-infected macrophages relies on Nef-dependent alteration of focal delivery of recycling compartments. Blood. 2010;115(21):4226-36.

108. Jambo KC, Banda DH, Kankwatira AM, Sukumar N, Allain TJ, Heyderman RS, Russell DG, Mwandumba HC. Small alveolar macrophages are infected preferentially by HIV and exhibit impaired phagocytic function. Mucosal Immunol. 2014;7(5):1116-26.

109. Kedzierska K, Azzam R, Ellery P, Mak J, Jaworowski A, Crowe SM. Defective phagocytosis by human monocyte/macrophages following HIV-1 infection: underlying mechanisms and modulation by adjunctive cytokine therapy. J Clin Virol. 2003;26(2):247-63.

110. Jouve M, Sol-Foulon N, Watson S, Schwartz O, Benaroch P. HIV-1 buds and accumulates in "nonacidic" endosomes of macrophages. Cell Host Microbe. 2007;2(2):85-95.

111. Moorjani H, Craddock BP, Morrison SA, Steigbigel RT. Impairment of phagosome-lysosome fusion in HIV-1-infected macrophages. J Acquir Immune Defic Syndr Hum Retrovirol. 1996;13(1):18-22.

112. Fields J, Dumaop W, Eleuteri S, Campos S, Serger E, Trejo M, Kosberg K, Adame A, Spencer B, Rockenstein E, et al. HIV-1 Tat alters neurona autophagy by modulating autophagosome fusion to the lysosome: implications for HIV-associated neurocognitive disorders. J Neurosci. 2015;35(5):1921-38

113. Dumas A, Lê-Bury G, Marie-Anaïs F, Herit F, Mazzolini J, Guilbert T, Bourdoncle P, Russell DG, Benichou S, Zahraoui A, et al. The HIV-1 protein Vpr impairs phagosome maturation by controlling microtubule-dependent trafficking. J Cell Biol. 2015;211(2):359-72.

114. Cinti A, Le Sage V, Milev MP, Valiente-Echeverria F, Crossie C, Miron MJ, Pante N, Olivier M, Mouland AJ. HIV-1 enhances mTORC1 activity and repositions lysosomes to the periphery by co-opting Rag GTPases. Sci Rep. 2017:7(1):5515.

115. Tomlinson GS, Bell LC, Walker NF, Tsang J, Brown JS, Breen R, Lipman M, Katz DR, Miller RF, Chain BM, et al. HIV-1 infection of macrophages dysregulates innate immune responses to Mycobacterium tuberculosis by inhibition of interleukin-10. J Infect Dis. 2014;209(7):1055-65.

116. O'Leary S, O'Sullivan MP, Keane J. IL-10 blocks phagosome maturation in Mycobacterium tuberculosis_infected human macrophages. Am J Respir Cell Mol Biol. 2011;45(1):172-80

117. Mwandumba HC, Russell DG, Nyirenda MH, Anderson J, White SA, Molyneux ME, Squire SB. Mycobacterium tuberculosis resides in nonacidified vacuoles in endocytically competent alveolar macrophages from patients with tuberculosis and HIV infection. J Immunol. 2004;172(7):4592-8

118. Deretic V, Vergne I, Chua J, Master S, Singh SB, Fazio JA, Kyei G. Endosomal membrane traffic: convergence point targeted by Mycobacterium tuberculosis and HIV. Cell Microbiol. 2004;6(11):999-1009.

119. Behar SM, Martin CJ, Booty MG, Nishimura T, Zhao X, Gan HX, Divangahi M, Remold HG. Apoptosis is an innate defense function of macrophages against Mycobacterium tuberculosis. Mucosal Immunol. 2011:4(3):279-87.

120. Moraco AH, Kornfeld H. Cell death and autophagy in tuberculosis, Semin Immunol. 2014;26(6):497-511.

121. Yuan Z, Fan X, Staitieh B, Bedi C, Spearman P, Guidot DM, Sadikot RT. HIV-related proteins prolong macrophage survival through induction of Triggering receptor expressed on myeloid cells-1. Sci Rep. 2017;7:42028.

122. Campbell GR, Rawat P, Bruckman RS, Spector SA. Human immunodeficiency virus type 1 Nef inhibits autophagy through transcription factor EB sequestration. PLoS Pathog. 2015;11(6):e1005018.

123. Mehto S, Antony C, Khan N, Arya R, Selvakumar A, Tiwari BK, Vashishta M, Singh Y, Jameel S, Natarajan K. Mycobacterium tuberculosis and human immunodeficiency virus type 1 cooperatively modulate macrophage apoptosis via toll like receptor 2 and calcium homeostasis. PLOS ONE. 2015;10(7):e0131767.

124. Collini PJ, Bewley MA, Mohasin M, Marriott HM, Miller RF, Geretti AM, Beloukas A, Papadimitropoulos A, Read RC, Noursadeghi M, et al. HIV gp120 in the lungs of antiretroviral therapy-treated individuals impairs alveolar macrophage responses to pneumococci. Am J Respir Crit Care Med. 2018;197(12):1604-15.

125. Patel NR, Swan K, Li X, Tachado SD, Koziel H. Impaired M. tuberculosismediated apoptosis in alveolar macrophages from HIV + persons: potential role of IL-10 and BCL-3. J Leukocyte Biol. 2009;86(1):53-60.
126. Coleman MM, Basdeo SA, Coleman AM, Cheallaigh CN, Castro CPd, McLaughlin AM, Dunne PJ, Harris J, Keane J. All-trans retinoic acid augments autophagy during intracellular bacterial infection. Am J Respir Cell Mol Biol. 2018;59(5):548-56.

127. Wolf AJ, Linas B, Trevejo-Nunez GJ, Kincaid E, Tamura T, Takatsu K, Ernst JD. Mycobacterium tuberculosis infects dendritic cells with high frequency and impairs their function in vivo. J Immunol. 2007;179(4):2509-19.

128. Stumptner-Cuvelette P, Morchoisne S, Dugast M, Le Gall S, Raposo G, Schwartz O, Benaroch P. HIV-1 Nef impairs MHC class II antigen presentation and surface expression. Proc Natl Acad Sci USA. 2001;98(21):12144-9.

129. Schindler M, Wildum S, Casartelli N, Doria M, Kirchhoff F. Nef alleles from children with non-progressive HIV-1 infection modulate MHC-II expression more efficiently than those from rapid progressors. Aids. 2007;21(9):1103-7.

130. Singh SK, Andersson AM, Ellegard R, Lindestam Arlehamn CS, Sette A, Larsson M, Stendahl O, Blomgran R. HIV interferes with Mycobacterium tuberculosis antigen presentation in human dendritic cells. Am J Pathol. 2016;186(12):3083-93.

131. White AG, Maiello P, Coleman MT, Tomko JA, Frye LJ, Scanga CA, Lin PL, Flynn JL. Analysis of 18FDG PET/CT imaging as a tool for studying Mycobacterium tuberculosis infection and treatment in non-human primates. J Vis Exp. 2017;127:e56375.

132. Lin PL, Ford CB, Coleman MT, Myers AJ, Gawande R, loerger T, Sacchettini J, Fortune SM, Flynn JL. Sterilization of granulomas is common in active and latent tuberculosis despite within-host variability in bacterial killing. Nat Med. 2014;20(1):75-9.

133. Esmail H, Lai RP, Lesosky M, Wilkinson KA, Graham CM, Coussens AK, On T, Warwick JM, Said-Hartley Q, Koegelenberg CF, Walzl G. Characterization of progressive HIV-associated tuberculosis using 2-deoxy-2-[18 F] fluoro-D-glucose positron emission and computed tomography. Nat Med. 2016;22:1090-3.

134. Thompson EG, Shankar S, Gideon HP, Braun J, Valvo J, Skinner JA, Aderem A, Flynn JL, Lin PL, Zak DE. Prospective discrimination of controllers from progressors early after low-dose Mycobacterium tuberculosis infection of cynomolgus macaques using blood RNA signatures. J Infect Dis. 2018;217(8):1318-22.

135. Suliman S, Thompson E, Sutherland J, Weiner RdJ, Ota MOC, Shankar S, Penn-Nicholson A, Thiel B, Erasmus M, Maertzdorf J, et al. Four-gene pan-African Blood signature predicts progression to tuberculosis. Am J Respir Crit Care Med. 2018;197:1198-208.

136. Zak DE, Penn-Nicholson A, Scriba TJ, Thompson E, Suliman S, Amon LM, Mahomed H, Erasmus M, Whatney W, Hussey GD, et al. A blood RNA signature for tuberculosis disease risk: a prospective cohort study. Lancet. 2016;387(10035):2312-22.

137. Whatney WE, Gandhi NR, Lindestam Arlehamn CS, Nizam A, Wu H, Quezada MJ, Campbell A, Allana S, Kabongo MM, Khayumbi J, et al. A high throughput whole blood assay for analysis of multiple antigenspecific T Cell responses in human Mycobacterium tuberculosis infection. J Immunol. 2018:200(8):3008-19.

138. Frediani JK, Jones DP, Tukvadze N, Uppal K, Sanikidze E, Kipiani M, Tran VT, Hebbar G, Walker DI, Kempker RR, et al. Plasma metabolomics in human pulmonary tuberculosis disease: a pilot study. PLoS ONE. 2014;9(10):e108854

139. Collins JM, Walker DI, Jones DP, Tukvadze N, Liu KH, Tran VT, Uppal K, Frediani JK, Easley KA, Shenvi N, et al. High-resolution plasma metabolomics analysis to detect Mycobacterium tuberculosis-associated metabolites that distinguish active pulmonary tuberculosis in humans. PLOS ONE. 2018;13(10):e0205398.

140. Weiner J 3rd, Maertzdorf J, Sutherland JS, Duffy FJ, Thompson E, Suliman S, McEwen G, Thiel B, Parida SK, Zyla J, et al. Metabolite changes in blood predict the onset of tuberculosis. Nat Commun. 2018;9(1):5208.

\section{Publisher's Note}

Springer Nature remains neutral with regard to jurisdictional claims in published maps and institutional affiliations. 